\title{
Adopting Gas Automobile Fuels (LPG \& CNG) into the Nigerian Transportation System
}

\author{
Adewale E. ADEGORIOLA, Ph.D ${ }^{1 *}$ Ibrahim Musa SULEIMAN ${ }^{2}$ \\ 1.Department of Economics, Federal University Lafia, Lafia, Nasarawa State, Nigeria \\ 2.International Energy Studies and Energy Economics, University of Dundee, Scotland, United Kingdom
}

\begin{abstract}
This study investigates and proposes the use of gas automobile fuels (LPG \& CNG) as transport fuel in Nigeria, by showing the policies and incentives that have been utilized by other countries and an analysis of the cost efficiency and environmental effect of the use of auto-gas fuels. The use of CNG and LPG as auto fuel in Nigeria presents benefits with regards to efficiency and environmental friendliness will be highlighted in this research work with emphasis on the economic advantage. Demand for natural gas is likely to overtake other fossil fuels due to its availability, accessibility, versatility and cleanliness. This research shows that adopting gas automobile fuels (LPG \& CNG) as an automotive fuel has few barriers but in the long run is very viable in terms of emissions of Green-house gases to the environment and financially economical. From the study, we suggest that policies and incentives would be helpful for the implementation of auto-gas as a transport fuel with regards to fiscal and regulatory such as; excise-duty exemption or rebate, grants/tax credits for gas fueling vehicles conversion/acquisition, vehicle sales-tax exemption or income/profit tax credit and more. If Auto-gas for automotive fuel is considered and implemented in the Nigerian Transportation system, it will move the Nigerian fuel market from an inelastic feature to an elastic feature.
\end{abstract}

Keywords: Gas, Automobile Fuels, Transportation System, Nigerian

DOI: $10.7176 / J E S D / 10-14-02$

Publication date:July $31^{\text {st }} 2020$

\section{Introduction}

In growing economies demand for fuel can be significant because energy drives economic growth coupled with increasing awareness of carbon emissions and climate change, alternative options for transportation fuels are actively being considered around the world. Fuels such as PMS, AGO and Fuel Oil are generally regarded as 'dirty fuels' due to their impact on the environment. However, the impact of gas on the environment is considered less severe; thus, the need to look at alternatives such as Liquefied Natural Gas (LPG) and Compressed Natural Gas (CNG) as fuel choices (Okon, 2018).

Autogas, which is Compressed Natural Gas and Liquefied Petroleum Gas used as a transport fuel, is the second most widely used and accepted alternative automotive fuel in use in the world today after ethanol. Global consumption of Auto-gas has been rising rapidly in recent years, reaching 26.7 million tons in 2016, an increase of 283000 tons, or $1.1 \%$, over 2015 and $3.7 \mathrm{Mt}$, or $16 \%$, up on 2000 . There are now almost 26.8 million Auto-gas vehicles in use around the world (Morgan, 2017). The challenges of global warming have compelled the quest for cleaner, better and safer fuels that would not be injurious to the ecosystem. PMS and AGO are the most widely used forms of petroleum fuels, and the more expensive. Autogas that is, Liquefied Petroleum Gas (LPG) and Compressed Natural Gas (CNG) are two other forms of hydrocarbon fuels.

Autogas use is still concentrated in a small number of countries: just five countries - Korea, Turkey, Russia, Poland and Italy - together accounted for just under half of global autogas consumption in 2016; the 23 countries surveyed in the 2017 World LP Gas Association (WLPGA) autogas incentive policies report accounted for $83 \%$. The share of autogas in total automotive-fuel consumption varies widely among those countries, ranging from a mere $0.1 \%$ in Spain and the United States to about $18 \%$ in Ukraine. Autogas makes up more than $10 \%$ of the automotive-fuel market in five other countries: Bulgaria, Korea, Poland, Serbia and Turkey.

The enormous disparity in the success of autogas in competing against the conventional automotive fuels, gasoline and diesel, is explained mainly by differences in government incentive policies. Sales of auto-gas - the most widely used alternative to conventional automotive fuels - have been growing quickly in counties such as Korea and Turkey, thanks to government policies to encourage the use of alternative fuels on account of its inherent environmental, practical and cost advantages over other such fuels. But in some countries, auto gas market development has been held back by ineffective or poorly-designed policies, such as unfavorable tax rates and regulations that fail to account fully for the social benefits of switching to auto gas (Morgan, Ocal \& Stohr, 2014).

The primary reason why governments in many countries actively encourage the use of auto gas and other alternative fuels is the environment. Auto gas out-performs gasoline and, especially, diesel, as well as some other alternative fuels in the majority of studies comparing environmental performance that have been conducted around the world. Auto gas emissions are especially low with respect to noxious pollutants. With respect to greenhousegas emissions, auto gas performs better than gasoline and, according to some studies, out-performs diesel, when 
emissions are measured on a full fuel-cycle basis and when the LPG is sourced mainly from natural gas processing plants (Morgan, 2017).

However, in practice, the effectiveness of actual policies and measures deployed does not always fully reflect the true environmental benefits of switching to Auto gas from conventional automotive fuels. The most effective auto gas incentive policies are those that help to make the fuel more competitive against gasoline and diesel and give a strong financial incentive for end user to switch to auto gas. In practice, the financial attractiveness of auto gas over other fuels depends essentially on two factors: the net cost of converting an existing gasoline vehicle (or the extra cost of buying a factory-built auto gas vehicle compared with an equivalent gasoline or diesel vehicle) and the pump price of auto gas relative to diesel and gasoline. In short, the vehicle owner needs to be compensated for the additional upfront cost through lower maintenance costs, of which fuel is the most important. The time it takes for the savings in running costs to offset the capital cost - the payback period - depends on the usage of the vehicle, that is, the average distance travelled monthly or annually. The payback period usually has to be less than two to three years to encourage commercial vehicle owners to switch; private individuals often demand a quicker return on their investment (Morgan, 2017).

According to United Nations' estimates Nigeria's population has grown 400\% to 180 million between 1960 and 2016 and to 200,801,334 in 2019 and with the accompanying by the rural to urban drift of the populace, the demand for transportation energy will increase. Despite these challenges, Nigeria continues to flare about 20 percent of associated gas in the oil exploration and production process. The Nigeria National Petroleum Corporation (NNPC) reported that oil producers flared about 51 percent of the associated gas produced between 1990 and 2010, a volume of about 459 billion cubic meters $(\mathrm{bcm})$. This volume is equivalent to 53 billion litres of gasoline, which is more than 14.5 years' worth of Nigeria's gasoline consumption (OECD, 2013).

To address the twin challenges of gas flaring and fuel shortages, the use of compressed natural gas (CNG) as an automotive fuel was proposed in the 1990s, to harness natural gas resources, but progress has been slow (Aderibigbe, 2016). Nigeria presently has an estimated total of 11.5 million automobiles plying the National Transportation Network at various levels (NBS, 2018). Aside from showing that a market exists for auto-gas use, this data exhibits the level at which greenhouse emissions are emitted into the atmosphere and further indicates the urgency for the introduction of Auto-gas as a cleaner alternative fuel choice.

Premium Motor Spirit (PMS) and Automotive Gas Oil (AGO) are the forms of petroleum fuel used in automobiles in Nigeria. With an estimated 11.7 million automobiles (National Bureau of Statistics, 2018), the carbon emissions from them are extremely high. Also, cost of production and fuel pump price of these fuels are high. In the long run, the use of these fuels is not sustainable, to the economy or the environment. There is no robust national fiscal policy that ensures cost reflective investments for auto gas, no fiscal policy that captures the switching cost of gas fuels as pertains to the Nigerian downstream domestic market The use of PMS and AGO as staple fuels for transportation is not sustainable for a petroleum-product import-dependent economy whose population growth momentum is almost three times its GDP growth 3.2\% and 1.8\% respectively. Financial burdens from PMS under recovery grew Nigeria's indebtedness to about 11 trillion naira as at 2015 (NBS, 2016).

Being signatories to the Paris Agreement, there is no concerted initiative by Nigeria by way of policy to increase carbon emission abatement levels. Introducing auto-gas as a staple fuel promises to put Nigeria on the path of energy sustainability, efficiency and self-sufficiency. This study examines the benefits of adopting autogas into the Nigerian Transport system, resulting in reduced fuel costs and carbon emissions. Adopting auto-gas as transport fuel will lead to fewer carbon emissions, lower cost for the public as well as removing the necessity of subsidy on PMS.

\section{Literature Review}

In recent years, as a result of limiting reserve of crude oil and the clamor for the deregulation of the petroleum sector of the nation's economy, there is need to look beyond liquid fuel (gasoline, diesel) as vehicular fuels. The viability of adapting natural gas for motor fuels had been presented. Natural gas as automobile fuel has a multiple of advantages over liquid fuel. These include high octane number, less negative effects on engine parts, low toxicity of effluents (low CO, NOX, and lead emissions.) Experiences of other countries that are presently using natural gas as automobile fuel are reviewed along with the efforts put in place by Nigeria through the Nigerian Gas Company (NGC) Limited to experiment the project. The need of government through the NGC to be fully involved in the planning and execution of a retrofit plan to optimize pipeline network and supply service of natural gas to refueling and refilling stations is also emphasized (Oghenejoboh \& Akpabio, 2002).

The public on the other hand requires enlightenment on the need to convert their vehicles to gas/gasoline powered, and incentives given for patronizing natural gas filling stations. A cohesive interplay of both national and corporate interests in policy formulation and implementation will harness effective distribution and utilization of natural gas within the Nigeria socio-economic sector (Oghenejoboh \& Akpabio, 2002).

Since the automobiles are the main source of transportation, its usage increases day by day. Thereby it is necessary to identify a cheaper fuel for it. The currently existing and widely used fuel named gasoline also called 
as petrol. The cost of this fuel day by day increases and also it will be exhausted in future after some years. Another problem currently using fuels is the exhaust. The exhaust consists of $\mathrm{NO}, \mathrm{CO}, \mathrm{CO}, \mathrm{SO}$, lead and other particulates which lead to air $\mathrm{x} 2 \mathrm{x}$ pollution and adverse effect on human beings. So, it is important to opt for alternate fuels, which are cheaper and less pollutant to environment (Srinivasan, Francis Luther King \& Purushothaman, 2014).

Ubani and Ikpaisong (2018) opined that natural gas is a clean-burning, safe fuel that can save you money at the pump while benefitting the environment and reducing Nigeria's dependence on petroleum. It is a naturally occurring mixture of gaseous hydrocarbon, non-gaseous non-hydrocarbons and gaseous non-hydrocarbons found in underground reservoir rocks either on its own (non-associated gas) or in association with crude oil (associated gas). Natural gas is today accepted as one of the best sources of energy for the world and for the future because of its environmentally-friendly nature compared to other kinds of fossil fuels. Nigeria is ranked as the seventh most natural gas endowed nation in the world and relaxes on number one spot in Africa as she seats on about one hundred and eighty-eight trillion cubic feet of natural gas deposits. Current opportunities to utilize gas in Nigeria include: Gas to reinjection schemes, Gas to power schemes, Gas to petrochemicals (as feedstock), LNG-Liquefied Natural Gas, LPG-Liquefied Petroleum Gas, and CNG-Compressed Natural Gas.

According to Ubani and Ikpaisong (2018), the use of Compressed Natural Gas (CNG) as auto fuel in Nigeria presents so much benefits with emphasis on the economic advantage. CNG is a product of compressing natural gas to one hundredth volumes it occupies at standard atmospheric pressure. A comprehensive economic analysis to determine the cost savings from driving a car on CNG against PMS considered the case of a motorist who covers an average of $100 \mathrm{~km}$ every day in the approximately thirty days that make a month was employed. Results established that running a car on CNG amounts to saving N1,143 daily and N34 290 monthly, the cost of converting the car from PMS-driven to CNG-driven is recovered before the end of the sixth month. From the sixth month to the end of the first year, savings of N211,402 is made. Savings of N411,408 is enjoyed each year after the first year. Running vehicles on $\mathrm{CNG}$ will greatly reduce the friction and troubles encountered in importing fuel into the country. This will also cut down largely the hardly available foreign exchange expended in bringing in PMS for fueling vehicles. To this end, the Nigerian Government should as a matter of national development ensure legal and regulatory framework encompassing both technical and commercial aspects for natural gas utilization in Nigeria. Worthy of note is the aspect of gas gathering, gas transmission and distribution which will further encourage the planting of $\mathrm{CNG}$ refueling stations that will serve the expected large fleet of natural gas vehicles. Currently, Green Gas Limited, a joint venture between Nigeria Gas Company (NGC) a Nigerian National Petroleum Corporation (NNPC) and NIPCO Plc. that has nine operational CNG refueling stations and others under construction is the only company driving the CNG revolution in the country.

Chikezie and Udoka (2013) stated that as the world grows and economies develop, global demand for energy will continue to grow dramatically. Demand for natural gas is likely to overtake other fossil fuels due to its availability, accessibility, versatility and cleanliness. For instance, the International Energy Agency (IEA) proposed in May 2012 that global demand for natural gas could rise more than 50\% by 2035, from 2010 levels. According to the Intergovernmental Panel on Climate Change (IPCC), global greenhouse gas (GHG) emissions must be reduced by 50 to 80 percent by 2050 to avoid dramatic consequences of global warming. In order to meet this growing energy demand and GHG reduction, we must develop all commercially-viable energy sources. As we know that no single energy source can meet the world's growing energy needs. We also need a more diverse energy mix which will enable energy security and help tackle the issue of climate change. Meeting this growing longterm societal demand requires that we develop all economic and environmentally-sound energy sources. Natural gas which is the cleanest compared to other fossil fuels is available to provide the world with a viable alternative. Its abundance, reliability, versatility and accessibility, will be a huge factor.

Based on the insights from the case study, consistent submissions of the participants of the semi-structured interviews and the outcome of the Delphi survey, the study concludes that several factors have hindered the adoption of CNG as a road transportation fuel in Nigeria. These factors are: Insufficient focus, Unconducive energy market structure, Limited access to funding, Weak transportation market structure, Weak institutions for vehicle standards enforcement and Low level of public awareness (Ogunlowo, 2016).

\subsection{Insufficient Focus and Misplaced Priority of Previous Policy on Natural Gas}

This has been characterized by the focus of government policy and legislation on abatement initiatives, rather than gas gathering and utilization, over a long period of time spanning 1969 to 2008; the absence of a clear policy and regulations on automotive use of natural gas in both the National Domestic Gas Supply Policy and the National Domestic Gas Supply and Pricing Regulation; focus on the development of an international gas export market for liquefied natural gas (LNG) and a regional gas market for piped natural gas (PNG); and absence of specific regulations and standards for natural gas vehicles (Ogunlowo, 2016).

\subsection{Unconducive Energy Market Structure}

This is seen in the inconsistent petroleum products pricing framework, which favors gasoline over other products 
and which is further compounded by the subsidy on gasoline; regulatory uncertainty caused by the non-passage of the PIB; absence of market coordination with respect to automotive use of natural gas; poor and limited gas transmission and distribution infrastructure; obsolete standards and operational guidelines in the downstream sector; arbitrariness in policy enforcement; a low technological and industrial base for energy consumption in the country, compounded by the total or near collapse of the few government-owned corporations with dedicated supply pipelines; the non-separation of regulatory and operating functions of NNPC; poor credibility of the erstwhile major bulk buyer, the government-owned Power Holding Corporation of Nigeria (PHCN); and lack of commitment by operators (Ogunlowo, 2016).

\subsection{Limited Access to Funding}

This is exemplified by poor access to long-term funding, due to inadequate local financing capabilities and sovereign and exchange risks with associated offshore borrowing, as well as the slow response of NNPC to cash calls with respect to joint venture operations with the international oil companies. Public safety concerns: This is mainly due to the general inexperience of the population with gas handling, the age and dilapidated state of the existing vehicle fleet, and dependence on imported, previously used vehicles. Technical and physical limitations: This is especially the case for the difficult physical terrain of the Niger Delta and given the limited number of appropriate reservoirs conducive for gas storage, due to the low gas-oil ratio (Ogunlowo, 2016).

\subsection{Weak Transportation Market Structure}

This is due to the higher cost of vehicles as a result higher import duties and inefficiencies and corruption in the ports, compounded by the higher cost of NGVs relative to conventional vehicles; lack of a comprehensive transport policy, leading to uncertainty in the policy environment on transportation; the absence of organized mass-transit companies and large fleet owners and managers with capacity to invest in central and private refueling infrastructure; the absence of vehicle emissions standards and the focus of vehicle importation policy on the fiscal regime and age of vehicle; absence of any regulations or guidelines on retrofitting standards (Ogunlowo, 2016).

\subsection{Weak Institutions for Vehicle Standards Enforcement}

The Vehicle Inspection Office (VIO), Nigeria Police Force and Nigeria Custom Service lack mechanisms to enforce the strict standards required for natural gas vehicles; and the limited number of OEM authorized and certified mechanics, and the preponderance of unschooled and uncertified mechanics that typically cut corners. Low level of public awareness: This is caused by the absence of any campaign to promote the automotive use of natural gas (Ogunlowo, 2016).

Table 1: Top Ten Autogas Markets

\begin{tabular}{llccc}
\hline S/N & \multicolumn{1}{c}{ Country } & Consumption (Thousand Tons) & Vehicles (Thousand) & Refueling Sites \\
\hline 1 & Korea & 3,515 & 2,185 & 2,031 \\
2 & Turkey & 3,142 & 4,440 & 10,426 \\
3 & Russia & 3,050 & 3,000 & 4,900 \\
4 & Italy & 1,659 & 2,211 & 3,940 \\
5 & Poland & 1,790 & 2,977 & 5,390 \\
6 & Thailand & 1,466 & 920 & 950 \\
7 & Ukraine & 1,385 & 2,250 & 3,500 \\
8 & Japan & 1,002 & 221 & 1,440 \\
9 & China & 990 & 165 & 550 \\
10 & Australia & 532 & 360 & 2,500 \\
11 & Rest of the World & 8,173 & 8,077 & 40,465 \\
& Total & 26,704 & 26,806 & 76,092 \\
\hline
\end{tabular}

Source: WLPGA/Argus (2017)

\section{Methodology}

The study adopts a comparative analysis of Auto-gas incentive programs in the world's largest Auto-gas markets. Reducing the environmental impact of transport activities is the main justification for governments to promote the use of Autogas and other alternative fuels. Pollution and global warming cause by rising concentrations of greenhouse gases in the atmosphere are prime examples of market failure, since the market fails to put a financial value or penalty on the cost of emissions generated by individuals or organizations. Air quality and the climate are, in economists' parlance, public goods, from which everyone benefits. Damage done to the environment is known as an external cost or externality. Governments have a responsibility to correct these failures, to discourage activities that emit noxious or greenhouse gases and to make sure that each polluter pays for the harm he causes to public goods. 


\subsection{Gas Fuels Adoption Policy}

\subsubsection{Policy Adoption of Gas fuels with Regards to Environment}

Reducing the environmental impact of transport activities is the main justification for governments to promote the use of autogas and other alternative fuels. Pollution and global warming caused by rising concentrations of greenhouse gases in the atmosphere are prime examples of market failure, since the market fails to put a financial value or penalty on the cost of emissions generated by individuals or organizations (OECD, 2013).

Air quality and the climate are, in economists' parlance, public goods, from which everyone benefits. Damage done to the environment is known as an external cost or externality. Governments have a responsibility to correct these failures, to discourage activities that emit noxious or greenhouse gases and to make sure that each polluter pays for the harm he or she causes to public goods.

Levying charges on polluting activities is effectively a way of internalizing these environmental externalities, although placing an exact financial value on them is extremely difficult and inevitably involves a large degree of judgment. A large number of studies have attempted to assess the health and economic costs of different types of emissions, including greenhouse gases. The Social Cost of Carbon (SCC), for example, is the marginal cost of emitting one extra ton of carbon $\left(\mathrm{as}_{2}\right)$ at any point in time. Estimates vary widely according to the assumptions made and methodological approaches used.

In principle, the most economically efficient approach to internalizing external costs is one that relies mainly on financial incentives, i.e. a market-based approach. In other words, the effective market price of the activity that gives rise to an environmental externality should be adjusted through the application of a tax and/or subsidy large enough to reflect the value or cost of that externality. Once an appropriate fiscal framework is in place, consumers and producers are free to make informed economic choices according to their own preferences. In the case of road transport, that involves taxing or subsidizing transportation in such a way that the financial costs to end users of the different fuel and vehicle options reflect their associated environmental cost (OECD, 2013).

In practice, developing effective transport and energy policies that take account of environmental externalities is extremely difficult - even if reliable quantitative estimates of external costs can be obtained. It is complex to apply taxes and subsidies exactly according to actual vehicle usage and the actual emissions produced during use, though technological developments may make this a practical solution in the future. And emission-trading schemes are similarly impractical for fuel use in the transport sector given the large number of users. Financial incentives have, thus, generally focused on fuel-based taxes, as they are simpler and politically less sensitive than measures that impact vehicle use directly, such as road pricing, even though evidence suggests that pricing vehicle use can be very effective. The earliest widespread experience of differential taxation to support environmental goals was the introduction of unleaded gasoline, where lower taxes relative to leaded fuel were extremely effective in accelerating its uptake.

More recently, similar incentives have been focused on encouraging the use of low Sulphur diesel and alternative fuels. The case for differential fuel taxes for to achieve environmental objectives is well established, though effective tax rates are rarely consistent with stated policy goals. Economic efficiency demands that the excise taxes levied on any given fuel should be applied at the same rate to all users, commercial and noncommercial Most governments deploy other complementary approaches that target vehicle use, modal choices and emissions performance rather than just the prices of transport fuels, as such broader approaches tend to be more effective in practice in reducing emissions (especially of greenhouse gases) from road vehicles. Such approaches seek to internalize implicitly the external environmental costs of road transportation. They may be aimed specifically at encouraging the use of clean fuels, including Auto gas and other alternative fuels, or discouraging the use of more polluting fuels (Morgan, 2017).

There is wide range of options at the disposal of policy makers within the normal policy-toolbox to promote the supply and use of alternative fuels, including LPG \& CNG. These measures complement broader measures to reduce emissions from road vehicles, including emission standards. The main approaches that governments could or do deploy are financial incentives and regulatory measures. Other measures include support for technology development and public awareness programs.

\subsubsection{Financial Incentives Policy for Gas Fuels Adoption}

Financial incentives can be directed at the fuels themselves or vehicles that are able to use them. The main measure that the countries surveyed in this report use to promote auto gas can take the form of a lower rate of excise duty, sales tax or its complete exemption. In some cases, commercial vehicles may enjoy a rebate on fuel taxes. These measures directly reduce the cost of running an alternative fuel vehicle (AFV) vis-à-vis gasoline and diesel vehicles and shorten the payback period on converting or acquiring the AFV. Since differences in excise duty show up in prices at the pump, the measure is also highly visible, raising public awareness of the potential cost savings from using alternative fuels. The lower the rates of duty and tax relative to other fuels, the bigger the financial incentive to switch (World Liquefied Petroleum Gas Association, 2014).

\subsubsection{Benefits of Gas Fuels on the Vehicle and Environment}

Where LPG is the sole fuel, experience has shown a number of benefits over petrol in respect of durability. Engine 
life is claimed to be typically 50\% longer as a result reduced cylinder bore wear during cold starting, since LPG does not wash oil off the cylinder walls and the lubricating oil has a longer effective life due to almost total absence of dilution. Combustion chamber and spark plug deposits are reduced, although spark plug life is not necessarily extended. The exhaust system durability is extended when operating solely on LPG fuel. And because LPG has a simple chemical composition, more complete combustion occurs leading to lower $\mathrm{CO}$ and $\mathrm{HC}$ emission into the environment (WLPGA, 2014).

\subsubsection{Benefits of Gas Fuels to Nigeria as Country with Natural Gas Endowment}

Nigeria with their own natural gas reserves can use the gas in place of the imported oil in order to reduce expenses on imports in the account balance of the country. This is because the use of domestic natural gas as a vehicle fuel can have positive effects on the current account balance of Nigeria. A data from Central Business Nigeria (CBN) revealed that from 2013 - 2017, a total of forex committed to imports in the country stood at $\$ 119.409$ billion. while the total forex committed to imports in the oil sector stood at $\$ 36.371$ billion which is about $13.5 \%$ of all imports made by the country.

\section{Discussion of Findings}

4.1 Comparative Analysis for LPG vs AGO and PMS

Table 2: Comparative Analysis for LPG Vs AGO and PMS under Prevailing Partially Regulated Regime

\begin{tabular}{llll}
\hline Descriptions & $\begin{array}{l}\text { LPG Consumption } \\
\text { (Kg) }\end{array}$ & $\begin{array}{l}\text { Diesel Consumption } \\
\text { (Litres) }\end{array}$ & $\begin{array}{l}\text { Petrol Consumption } \\
\text { (Litres) }\end{array}$ \\
\hline Fuel & 3.00 & 4.91 & 6.2 \\
Unit price of fuel (Naira) & 248.03 .03 & 265.00 & 145.00 \\
Fuel cost/ hour (Naira) & 774.00 & 1301.15 & 889 \\
Naira saving on LPG relative to Diesel and Petrol & 117.88 & 7.32 \\
\%Naira saving on LPG relative to Diesel and Petrol & $16.56 \%$ & $1.22 \%$ \\
\hline
\end{tabular}

Source: NNPC, 2018

From the analysis it can be deduced that: The percentage cost saved when running the $25 \mathrm{kva}$ genset on LPG is $16.56 \%$ instead of diesel. A minimum of N117.32 is saved with a $25 \mathrm{kva}$ genset running on LPG instead of Diesel, For every 1-hour runtime. Despite the subsidy on petrol, percentage savings for a 37HP car engine running on Auto gas instead of petrol is $1.22 \%$. A minimum of N7.32 is saved with a $37 \mathrm{HP}$ car engine running on Auto gas instead of Petrol, for every 1-hour runtime.

\subsection{Analysis of Cumulative Savings on 25kva /37hp LPG Engine over PMS and AGO Engines Under a} Prevailing Regime

Table 3: Periodic Savings using LPG on 37Hp/25Kva Engine (4-cylinder engine Toyota)

\begin{tabular}{lll}
\hline Period (years) & AGO (Naira) & PMS (Naira) \\
\hline 1 & $1,018,440.00$ & 63,288 \\
2 & $2,036,880.00$ & $126,576.00$ \\
3 & $3,005,320.00$ & $189,864.00$ \\
4 & $4,073,760.00$ & $253,152.00$ \\
5 & $5,092,200.00$ & $316,440.00$ \\
6 & $6,110,640.00$ & $379,782.00$ \\
\hline
\end{tabular}

Source: NNPC, 2018

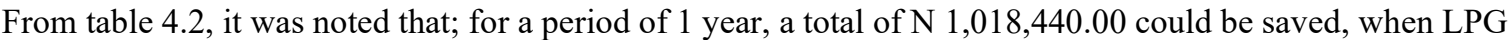
is used instead of AGO to run a 37hp engine, and this amount increases to N 6,110,640.00 for a 6-year period and also for a period of 1 year, a total of N 63,288.00 is saved when LPG is used instead of PMS to run a 37hp engine, and this amount increases to N 379,728.00 for a 6-year period.

The technology to run gasoline engine vehicles on LPG has been around for many years and has been widely used in Europe, the U.K and other countries. Conversion of gasoline vehicles to run on LPG required the use of standard conversion kits. The use of the conversion kits depends on the type of generation of the vehicles. LPG fuel systems are commonly classified into three. They are first generation, (i.e. mechanical controlled LPG system with a carburetor as fuel metering device), second generation (i.e. electronically controlled carburetion systems) and third generation (i.e. LPG injection systems). The system introduces gas to the engine in a vapor form through the inlet manifold. This then gets to the LPG reducer, which controls the inlet of fuel into the engine. The fuel delivery is controlled by a stepper motor, which gives the most efficient fueling at all times. 


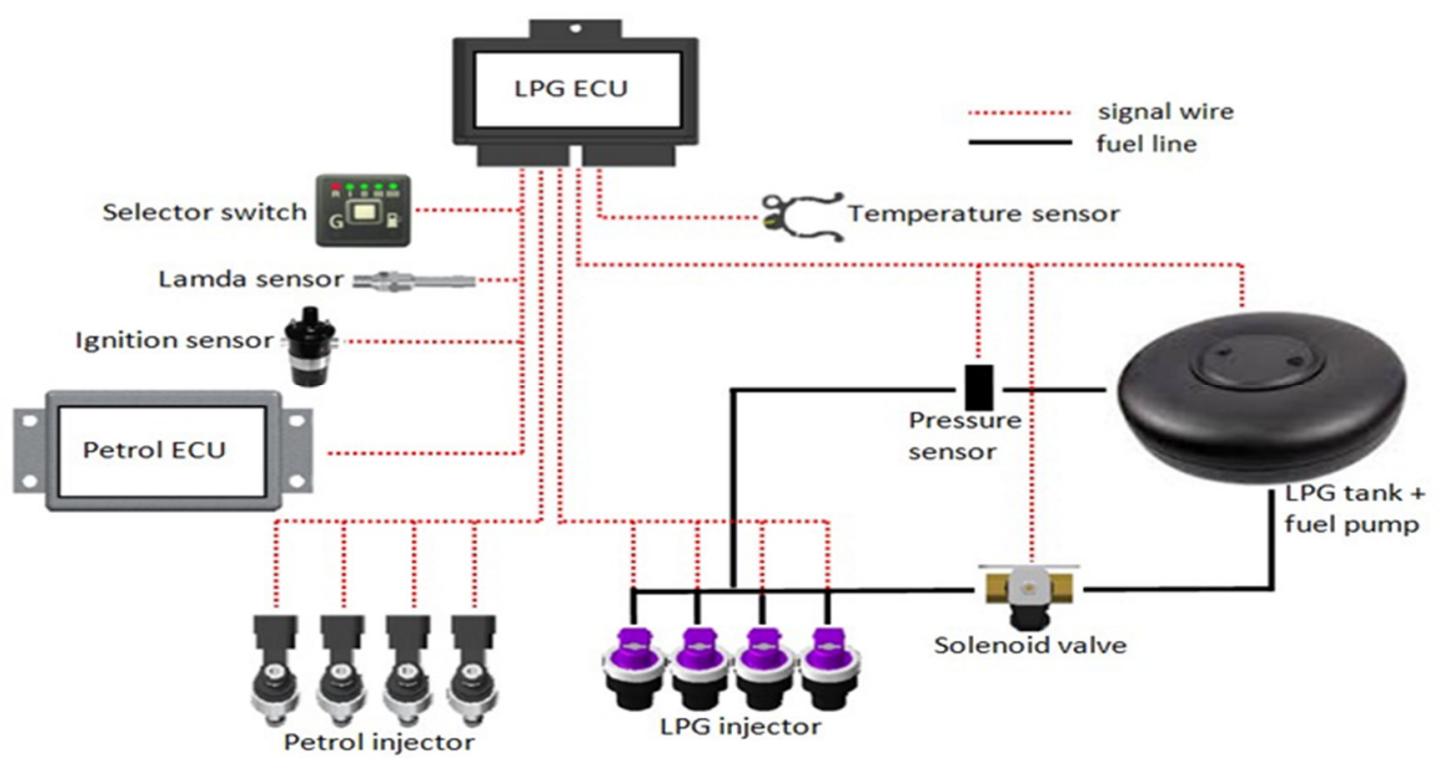

Figure 1: Installation Diagram of LPG conversion kit.

Some of the components needed for conversion include; fuel tank, regulator, fuel rails, adapter, plugs, new fueling computer and LPG injectors. The penetration of auto gas into the market largely depends on how competitive the fuel is against gasoline and diesel (i.e. how financially attractive it is for an end user to switch to gas fuels). It also largely depends on the cost of converting the vehicle and the pump price of Auto gas relative to diesel and gasoline.

Since converting a vehicle to run on auto gas involves upfront capital expenditure (Depending on which style of system is fitted, installation costs average around $\$ 2,500$ for a basic vapor mixer to $\$ 4,500$ for a sequential injection system) and some minor inconvenience. The owner needs to be compensated through lower running costs, of which fuel is the most important. The time it takes for the savings in running costs to offset the capital cost (the payback period) depends on the usage of the vehicle, i.e. the average distance travelled monthly or annually. Critical to the payback period, is the extent to which government incentives lower the initial expenditure (through subsidies) and fuel costs (through favorable taxation).

In practice, the payback period generally has to be less than two to three years to encourage commercial vehicle owners to switch; private individuals often demand an even quicker return on their investment. The absolute level of tax on Auto gas matters less than the how high it is in absolute terms relative to conventional fuels, as that is what helps determine the size of the financial saving that can be made from switching to Auto gas.

\section{Conclusion}

The study examine the policy option for auto-gas (LPG \& CNG) as transport fuels in Nigeria, by showing the policies and incentives proposed by governments of other countries that use Auto gas successfully. And from study, it is therefore that several policies and incentives would be helpful for the implementation of auto-gas as a transport fuel with regards to fiscal and regulatory such as; excise-duty exemption or rebate, grants/tax credits for auto-gas fueling vehicles conversion/acquisition, vehicle sales-tax exemption or income/profit tax credit (purchasers and original equipment manufacturers), tax credits for investment in distribution infrastructure and R\&D, mandatory sales/purchase requirements for public and/or private fleets (with enforcement), coherent and appropriate health and safety regulations, Standards to harmonize refueling facilities, Vehicle-conversion standards, Government own-use of Autogas Fuel Vehicles, Information dissemination, public awareness campaigns, Voluntary agreements with Original Equipment Manufacturers to develop, market Autogas Fuel Vehicles technologies and Direct funding for research, development, demonstration and deployment of Autogas Fuel Vehicles. It is recommended that if the option of Auto-gas for automotive fuel be considered and implemented in the Nigerian Transportation system, it will move the Nigerian fuel market from an inelastic feature to an elastic feature.

\section{References}

Australian Government department of Resources, Energy and Tourism [AGDRET] (2011). Strategic framework for alternative transport fuels, December, Canberra.

Biscoff, R, Akple, M, Turkson, R. \& Klomegah, W. (2012). Scenario of the emerging shift from gasoline to LPG fueled cars in Ghana: A case study in Ho Municipality. Available at: https://www.nigerialpgas.com/downloads/780368.pdf, accessed: 23 May 2019.

Ediri, E. (2018). NIPCO converts 5,600 vehicles engines from petrol to gas, viewed 3 June 2019, 
< https://www.vanguardngr.com/ 2018/10/nipco-converts-5,600-vehicles-engines-from-petrol-to-gas/ > accessed $5^{\text {th }}$ July, 2019

Fikayo, O. (2018). Central Bank of Nigeria (CBN) reveals how much Nigeria spends on fuel importation, viewed 5 June 2019, < https://nairametrics.com/2018/05/08/bn-reveals-how-much-nigeria-spends-on -fuelimportation/> accessed $5^{\text {th }}$ June, 2019

World Liquefied Petroleum Gas Association A, LPG Exceptional Energy, (2014). Autogas Incentive Policies; A country-by-country analysis of why and how governments encourage Autogas and what works; 2014 Update

Morgan, T. (2017). Autogas Incentive Policies: A Country-By-Country Analysis of Why and How Governments Encourage Autogas And What Works, s. 1.: s. n.

Nuhu, Y. (2015). Autogas, is Nigeria Ready? Available at: https://www.nigerialpgas.com/downloads/780368.pdf, accessed: 19 May 2019.

Okon, T. (2018). NGRI Analysis of PMS Subsidy in Nigeria.

Organization for Economic Corporation \& Development [OECD] (2013). Taxes energy use: A graphical analysis, OECD, Paris.

Organization Economic Corporation and Development [OECD] (2013). Annual Report on the OECD Guidelines for Multinational Enterprises

Ogunlowo, O. O. (2016). Exploration of Compressed Natural Gas as an Automotive Fuel in Nigeria, s. 1.: s. n.

Oyeniyi, M. J. (2016). Possibilities of Compressed Natural Gas Vehicle Development in Lagos State Road Transport System: A Viable Concept for Nigeria Road Transport System, s. l.: s. $n$.

Robert, M. (2016). Nigeria introduces auto-gas-powered cars, viewed 3 June 2019, < https://gazeo.com/up-todate/news/2016/Nigeria-introduces-autogas -powered-cars, news, 9950.html $>$ accessed $5^{\text {th }}$ June, 2019

Srinivasan, V., Francis Luther King, M. \& Purushothaman, T. (2014); Alternate Fuel - A Literature Review

Tasic, T., Pogorevc, P., \& Brajlih, T. (2011). Gasoline and LPG Exhaust Emissions Comparison, APEM Journal 2011

Ubani, E. C., \& Ikpaisong, S. U. (2018). Use of CNG as Auto fuel in Nigeria, European Journal of Engineering Research and Science.

World LP Gas Association [WLPGA] (2001). Developing a sustainable autogas market: Guidelines for policemakers, WLPGA, Paris 